\title{
The Expanding Riboverse
}

\author{
Sergey O. Sulima ${ }^{1}$ and Jonathan D. Dinman ${ }^{2, *} \mathbb{D}$ \\ 1 Biopharmaceutical New Technologies (BioNTech) Corporation, 55131 Mainz, Germany; \\ sergey.o.sulima@gmail.com \\ 2 Department of Cell Biology and Molecular Genetics, University of Maryland, College Park, MD 20742, USA \\ * Correspondence: dinman@umd.edu
}

Received: 3 September 2019; Accepted: 2 October 2019; Published: 5 October 2019

\begin{abstract}
Subverting the conventional concept of "the" ribosome, a wealth of information gleaned from recent studies is revealing a much more diverse and dynamic ribosomal reality than has traditionally been thought possible. A diverse array of researchers is collectively illuminating a universe of heterogeneous and adaptable ribosomes harboring differences in composition and regulatory capacity: These differences enable specialization. The expanding universe of ribosomes not only comprises an incredible richness in ribosomal specialization between species, but also within the same tissues and even cells. In this review, we discuss ribosomal heterogeneity and speculate how the emerging understanding of the ribosomal repertoire is impacting the biological sciences today. Targeting pathogen-specific and pathological "diseased" ribosomes promises to provide new treatment options for patients, and potential applications for "designer ribosomes" are within reach. Our deepening understanding of and ability to manipulate the ribosome are establishing both the technological and theoretical foundations for major advances for the 21st century and beyond.
\end{abstract}

Keywords: ribosome; specialization; heterogeneity; cancer; ribosomopathies; translational fidelity

\section{Introduction}

Contrary to beliefs held by children and certain politicians, the universe does not revolve around ourselves. The Copernican revolution gave rise to a series of profound changes, initiating a shift from a world view dominated by opaque and unknowable supernatural beings to one governed by laws that are accessible to the human mind through the scientific process. In our lifetimes, the discovery of exoplanets, gravitational waves, and multiverse theory is arguably having similar impact. However, the concept of strength through diversity, while a cornerstone of the new cosmology, evolutionary biology and liberal politics, is something that is only emerging in the molecular biosciences. The prevailing view of messenger RNAs (mRNAs) carrying an invariant genetic code that is translated by monochromatic ribosomes to produce identical proteins is only now becoming viewed as simplistic. We are on the cusp of appreciating how diversity at the molecular level may confer selective advantages by broadening both the coding and buffering capacity of the cells and organisms.

When discussing the molecular apparatus that translates genetic information in mRNAs into proteins, our very language betrays the prevailing monolithic view: We tend to refer to "The Ribosome", as if this complex assemblage of RNAs and proteins is uniform in every living organism. This assumption was not the case in the beginning. After the discovery that genetic information is encoded in nucleic acids and that it is decoded by RNA-rich ribosomes, Francis Crick briefly proposed that each ribosome encoded its own unique protein [1], an idea that was quickly discarded by the discovery of mRNA. A western cultural bias for unifying theories led to the near universal adoption of a single model organism (Escherichia coli), while technological limitations necessitated making steady-state measurements in bulk systems: These factors helped to cement the idea of "The Ribosome" 
in the scientific domain. Even as recently as the turn of the millennium, when atomic resolution structures were first being revealed, the technological reliance on ribosomes that were uniformly packaged into crystals reinforced this monolithic ribosome bias.

A closer look at the literature reveals plentiful contradictory evidence going back as far as the late 1980s. The observation that the interactions between ribosomes and ternary complex were enhanced in isolates from naturally occurring E. coli strains, and that this correlated with enhanced growth and survival phenotypes relative to laboratory strains, suggested that ribosomal diversity may have a selective advantage in nature [2]. Another early hint came from findings that deletion of one but not the other ribosomal protein paralogous genes impaired the ability of Saccharomyces cerevisiae to propagate the yeast "killer virus" [3]. Later studies using the yeast deletion collection revealed differences in many cellular and metabolic functions [4] and translational accuracy [5], and a recent study revealed that ribosomal protein deletion-specific differences in gene expression signatures were associated with cellular growth rate [6]. Additionally, tissue-specific ribosomal heterogeneity observed both at the level of core ribosomal proteins and regulation suggests that specialized ribosomes naturally exist (reviewed in $[7,8]$ ). More recent studies have revealed requirements for specific ribosomal proteins for translation of cellular mRNAs containing internal ribosome entry site (IRES) elements during mouse development [9], and translational regulation in Drosophila melanogaster spermatogenesis [10]. Thus, similar to how the discovery of the first exoplanet, 51 Pegasi $b$, revolutionized our understanding of our place in the universe [11], recent evidence supporting the existence of specialized ribosomes has changed our view of the "riboverse". Here, we borrow terminology from astronomy and explore this constantly expanding riboverse, and the implications of this growing knowledge on cellular life, industrial applications, and therapeutics.

\section{Aliens Among Us}

Mammalian ribosomes are $80 \mathrm{~S}$ particles consisting of 80 ribosomal proteins (RPs) and 4 ribosomal RNA (rRNA) molecules in an approximately 1:1 mass ratio. However, other seemingly alien, "specialized" ribosomes have always thrived in plain sight. Several salient examples are discussed below.

\subsection{Mitoribosomes and Chlororibosomes}

The vast majority of the human proteome is synthesized by cytoplasmic or endoplasmic reticulum-associated ribosomes. However, 13 proteins of the mitochondrial oxidative phosphorylation machinery are translated exclusively by mitochondrial ribosomes (mitoribosomes), assembled from special mitochondrial RPs (encoded by nuclear DNA) and rRNAs encoded in the mitochondrial genome. Mitochondria are generally believed to be descendants of an ancient bacterium that entered into a symbiotic relationship with a primordial single-cell organism. As a result, the $55 \mathrm{~S}$ mitochondrial ribosomes both structurally and dimensionally more closely resemble ribosomes found in modern day bacteria, rather than those in eukaryotic cells. Mitoribosomes, however, display a 2:1 protein-to-rRNA mass ratio, much higher, than the 1:2 ratio in bacterial ribosomes. Mitoribosomes also replaced large parts of their non-core rRNA components with proteins as part of a devolutionary process, similar to observations of other symbionts and parasites [12]. A close examination of the mitoribosome structure reveals that the new proteinaceous component replaced rRNA around its periphery, creating an outer "shell" around the conserved catalytic rRNA core [13]. This suggests that these ribosomes developed a kind of "armor" to protect their catalytic rRNA cores from attack by reactive oxygen species, which are produced in abundance by the process of oxidative phosphorylation in mitochondria. Thus, we suggest that mitoribosomes may have become "specialized" to function in this particularly harsh environment.

Chloroplasts are also endosymbionts with their own genomes (plastome) and bacteria-like 70S ribosomes. While the general protein-to-rRNA mass ratio of chlororibosomes does not differ much from those in bacteria, they do contain unique rRNA features, five chloroplast-specific ribosomal proteins, and unique protein extension elements. These enable the specialized function of chlororibosomes 
by promoting the association of translation factors involved in light- and temperature-dependent control of plant protein synthesis [14,15]. These too may be considered to have become "specialized" to optimize protein expression in the unique environment of the chloroplast.

\subsection{Extreme Ribosomes}

The first atomic resolution structures were generated using ribosomes that are specialized to function in extreme environments [16-18]. The organisms from which they were purified, Thermus thermophilis and Haloarculum marismortui, evolved to thrive in environments of high temperature and in high osmolarity, respectively. Biochemically, such conditions tend to destabilize non-covalent interactions, particularly hydrogen bonds and salt bridges. Accordingly, the biomolecules synthesized by extremophiles have evolved to maximize stability, traits which make them ideal for crystallization studies. Thus, one may consider these ribosomes optimized to ideally function in their respective extreme environments. Given the ancient origins of the ribosome and its central role in biology, the idea that ribosomes can become environmentally specialized has profound implications for the field of astrobiology.

\subsection{Ribosomes of Parasites}

Parasites tend to be minimalists because a) their host organisms are able to meet most of the metabolic needs, and $b$ ) their requirements for small genomes that can be rapidly replicated. Their ribosomes also tend to follow the trend towards minimalization. For example, microsporidia are eukaryotic parasites that have successfully adapted to parasitize almost all animals. Their genomes have condensed to be the smallest known in the Eukaryota, and their mitochondria are rudimentary. A recent cryo-EM analysis of Vairimorpha necatrix revealed the smallest known eukaryotic cytoplasmic ribosome to date [19]. The rRNA from this species has been reduced to a functionally conserved core due to the loss or severe compaction of all of the eukaryote-specific expansion segments, and it lacks two eukaryote-specific ribosomal proteins, eL38 and eL41. Furthermore, this species lacks the 5.8 rRNA, whose core sequences have been fused with the large subunit rRNA to create a unique $23 \mathrm{~S}$ rRNA species. Interestingly, these ribosomes also associate with MDF1 and MDF2, distinct dormancy factors that may allow these organisms to save energy by storing inactive, "hibernating" ribosomes when they are not needed for active protein synthesis, e.g., during the spore stage.

Trypanosomes comprise a genus of parasitic flagellated protozoa in the class Kinetoplastea, best known for causing a variety of infectious diseases, including sleeping sickness, cutaneous leishmaniasis, and Chagas disease. Unlike the microsporidia, which have minimized rRNA content, trypanosomal rRNAs have become enlarged, containing unusually large expansion segments, a large rRNA domain that is not found in other eukaryotes, and additional rRNA insertions [20]. Additionally, some of the ribosomal proteins contain unique extensions, which enable the formation of four inter-subunit bridges that are not observed in other eukaryotic ribosomes. Curiously, although the genomic rDNA genes encode the four rRNA species, the large subunit rRNA is cleaved into six unique pieces. The functional aspects of these unique features are currently unknown.

The Apicomplexia include the genus Plasmodia, best known as the parasites responsible for malaria. Interestingly, Plasmodium species carry two cytoplasmic ribosome variants with different rRNA compositions. One of these is expressed in the mosquito vector, and the other is present in the mammalian host, although both can simultaneously occur for limited periods of time [21]. Presumably, these maximize the ability of the organism's ribosomes to function in the very different environments of the insect vector and human host.

\section{Aliens Within Us}

In contrast to the ideas presented in the previous section, the concept of "specialized" ribosomes is more popularly associated with otherwise normal cytoplasmic ribosomes that, by virtue of a change in protein or rRNA content, are endowed special properties. The reader is directed to reviews by 
the Barna [8] and Blanchard research groups [22], whose research efforts deeply explore this topic of inquiry in mammalian and bacterial cells, respectively. Here, we explore emergent and perhaps more controversial examples of this type of specialization.

\subsection{Ribosomal Protein Paralogs}

Mammalian ribosomes harbor 80 ribosomal proteins. However, the existence of splice variants and paralogous versions of some of these suggests that incorporating one in favor of another may confer some specialized function (reviewed in [23]). Of particular interest are instances of ribosomal proteins that originally arose from gene duplication and are actively expressed, but which also have variations in their amino acid sequences. These include three versions of the RPS4 gene (RPS4X on the human $X$-chromosome, and RPS4Y1E2, both residing on the Y-chromosome), and genes encoding "ribosomal protein-like" proteins (RPL3L, RPL7L, RPL10L, RPL22L, RPL24D1L, RPL26L, RPS27L, RPL36aL, and $R P L 39 L)$. All of these are actively transcribed. RPL7L and RPL24D1 are currently thought to be exclusively involved in ribosome assembly and not incorporated into actively translating ribosomes. However, the hypothesis that one or both of these may be incorporated into mature ribosomes devoted to some special purpose remains to be disproved. Perhaps the strongest evidence for specialization comes from work on RPL3L, which appears to be exclusively expressed in striated muscle tissue [24]. Hypertrophic stimulus of skeletal muscle inhibited Rpl3lp expression to $20 \%$ of baseline levels, while increasing the expression of Rpl3p approximately five-fold, suggesting that Rpl3lp functions as a negative regulator of muscle growth. This is supported by the observation that induction of Rpl3lp expression in myoblasts during myotube formation greatly impaired myotube growth myoblast fusion. Furthermore, muscle growth requires active ribosome biogenesis [25]. Given the key role of ribosomal protein L3 in ribosome biogenesis and function [26], we suggest that mature muscles may utilize ribosomes harboring Rpl3lp instead of Rpl3p to retain homeostasis in mass. Stimuli that lead to muscle growth, such as injury and exercise, may cause striated muscle cells to switch to ribosomes harboring Rpl3p.

\subsection{Immunoribosomes}

The plasma membranes of nucleated cells in jawed vertebrates present Major Histocompatability Complex (MHC) Class I proteins in combination with antigenic peptides. These peptides are proteolytic products derived from cellular proteins. It has been proposed that defective ribosomal products (DRiPs) are a major source of these antigenic peptides [27]. The linkage between protein synthesis and MHC Class I antigen production prompted the proposal of a special class of ribosomes, the "immunoribosome", which is specifically dedicated to producing DRiPs [28]. While still controversial, a substantial body of evidence has emerged supporting this immunoribosome hypothesis over the past decade (reviewed in [29]). Going forward, the challenge will be to demonstrate the presence of such dedicated ribosomes using biochemical and/or genetic approaches. Success in this endeavor may have far-reaching consequences on our understanding of how homeostasis at the cellular level may be linked to immune surveillance at the organismal scale.

\subsection{Onco-Ribosomes}

In addition to the well-described ribosomal mutations in the congenital ribosomopathies, mutations in several ribosomal proteins in somatically acquired cancers have recently been described (reviewed in [30-32]). For example, alterations in RPs such as RPL5 (uL5), RPL10 (uL16), RPS15 (uS19), RPL11 (uL15), and RPL22 (eL22) have been described in 10-40\% of multiple tumor types. Studies of some of these suggest that, in addition to negatively impacting ribosome assembly similarly to RP mutations in ribosomopathies, the somatic RP mutations also influence ribosomal function, resulting in an oncogenic rewiring of the cellular protein expression profile. A well-studied example is the RPL10-R98S mutation in T cell leukemia, which promotes specific overexpression of the oncogenic JAK-STAT signaling cascade [33], IRES-dependent overexpression of the anti-apoptotic factor BCL2 [34], and 
both transcriptional and translational upregulation of serine and glycine biosynthesis [35]. Other examples include elevated expression of the oncogene c-MYC upon RPL11 inactivation [36], induction of stemness factor Lin28B by RPL22 inactivation [37], and altered translation of the critical hematopoietic transcription factor GATA1 in the RP-mutant ribosomopathy Diamond Blackfan anemia, which is in turn associated with a high risk of cancer progression [30,38]. More generally, ribosomal protein lesions have recently been described to promote cellular oxidative stress and increased mutagenesis [39].

Aside from mutations in RPs, rRNA modifications such as methylation and pseudouridylation are frequently altered in cancer cells [40]. It is tempting to speculate that unique modification patterns could also translate into unique gene expression patterns. In support of this, disruption of dyskerin, which catalyzes pseudouridylation, or of small nucleolar RNAs (snoRNAs) that guide dyskerin to rRNA is found in many cancers and can impair the translation of tumor suppressor-encoding mRNAs [40]. While it is too early to definitively proclaim the existence of an onco-ribosome, the recent studies supporting a specialized function of ribosomes in cancer underscore that ribosomal diversity can play a key role in human disease.

\section{The Expanding Universe of Ribosome Diversity}

The number of known exoplanets is now in the thousands. Taking into account the possible variations in parameters such as mass, orbit, composition, and distance to its star or stars, the number of conceivable unique planets approaches infinity. In parallel, the large number of known and possible ribosomes might be thought of as a constellation of ribosomes, which we call the "ribo-system" (Figure 1).

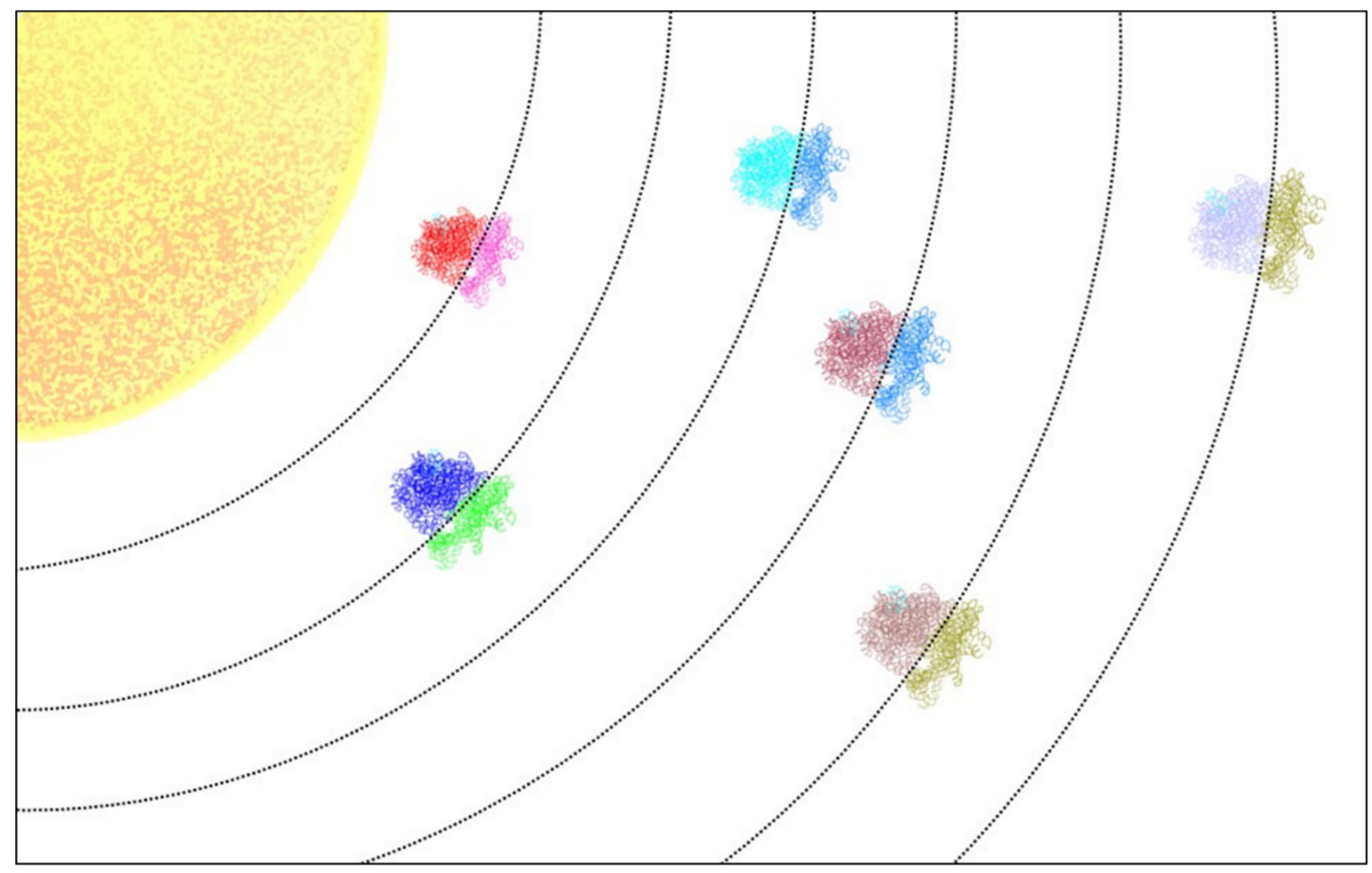

Figure 1. The ribo-system. Various types of ribosomes populate the known riboverse. Each type of ribosome is specialized for particular environments, which are represented by orbits in the above image. Each orbit corresponds to each ribosomal species" "habitable zone".

The rate of expansion in our knowledge of the degree of heterogeneity among ribosomes is similarly expanding, representing an exciting field of research. In addition to the different ribosomal protein paralogs discussed above, the functional importance of differences in their post-translational modification is beginning to emerge. 
Recent advances, particularly in single-cell sequencing and quantitative mass spectroscopy, are helping to bring the visible riboverse into sharper focus. In mammals, the observation of tissue-specific patterning defects in mice lacking the RPL38 gene and its linkage to defects in translation of specific homebox (HOX) mRNAs represented a seminal breakthrough because of its implications for ribosome specificity in developmental biology [41]. The demonstration of the importance of this protein for translation of IRES-containing mRNAs created a new paradigm with regard to ribosome-mediated control of gene expression [9]. However, the idea of generating heterogeneity through subtraction [42] is less appealing than showing specificity through substitution of one ribosomal protein variant for another, e.g., the Rpl31 case described above. Later, sophisticated proteomics analyses revealed non-stoichiometric levels of ribosomal proteins, their association with various classes of other proteins, and association with different transcript sub-pools, painting a picture of ribosomes specialized by the ability of intrinsic protein content to recruit specific trans-acting factors [43,44]. Similarly, the evolution of rRNA expansion segments has been found to provide new platforms for binding trans-acting factors required for recruitment of specific mRNA classes [45].

Ufmylation is a metazoan-specific post-translational modification in which UFM1 proteins are conjugated to particular ribosomal proteins. The finding that differences in ufmylation confers differences in specificity for trans-acting proteins suggests another route for specialization via differences in post-translational modification of ribosomal proteins [43]. Since then, evidence for such has steadily accumulated [46-56]. Post-transcriptional modification of ribosomal rRNAs presents a similar path to ribosome specialization $[57,58]$. In particular, the recent findings of variably methylated rRNA bases [59] and of changes in rRNA modification levels in response to external stimuli [60] suggest another avenue through which raised ribosome function and specificity may be regulated.

Ribosome specialization can also be achieved through allelic variation, the most well-documented example of which comes from recent studies of rRNA. For example, the E. coli genome contains seven distinct rRNA operons, each with their specific sequence variants [61]. RNAseq analyses were used to detect differences in the utilization of specific rRNA operons in response to nutrient limitation-induced stress, and these correlated with changes in ribosome function, gene expression, and cellular physiology, thus demonstrating specific roles for rRNA allelic variants [62]. In eukaryotes, rDNA copy number varies widely, and a cursory analysis of the human and mouse rDNA sequences revealed the potential for sequence heterogeneity within rDNA operons [63]. More recently, a meta-analysis of human and mouse genome databases identified pervasive intra- and inter-individual nucleotide variation in the 5S, 5.8S, $18 \mathrm{~S}$, and $28 \mathrm{~S}$ ribosomal RNA (rRNA) genes of both human and mouse, and ribosomes bearing variant rRNA alleles were found to be present in the actively translating ribosome pool [64]. These findings strengthen the idea that physically and functionally heterogeneous ribosomes may be important for normal physiological development and homeostasis and, conversely, in pathological processes. Allelic variation may also play an important role in population biology and evolution. This may provide a means though which a species could be pre-adapted to survive fluctuations in environmental conditions, e.g., climate change or location-specific differences in micronutrient availability.

\section{Conclusions and Perspectives}

\subsection{Medical Implications of the Riboverse}

Mirroring the inappropriate moniker "The Ribosome", we frequently refer to "cancer" as if it were one disease. However, to borrow from a Buddhist expression — there are many paths to enlightenment. In the cancer context, this refers to the path towards transformation, and almost no two cells follow the exact same path. Cancer thus ultimately encompasses many diseases. And heterogeneity is a hallmark of cancer at every level, as even one patient's tumor often displays several mutant clones, and still, within one clone, inter-cellular variability. To therapeutically overcome the tremendous hurdle posed by cancer's heterogeneity, it is essential to continuously improve the technologies illuminating the altered wiring of cancer cells at the DNA, RNA, and protein levels. 
While proteins are the chief cellular performers, tumor protein biology has been largely inaccessible and under-explored, as proteomics technologies have lagged for several decades behind other -omics technologies. The flow from DNA to RNA to protein is accompanied by an exponential increase in complexity, and this entire layer of additional potential variation within tumors has thus largely remained out of view. The cancer genome atlas (TCGA) contains full transcriptome, exome, and genome data for thousands of tumor samples, but the first full quantitative mass spectrometry-based proteomic descriptions of these cancer datasets are only now appearing (e.g., [65]). We have just begun to build correlations between tumor genomes, transcriptomes, and proteomes, giving rise to terminology such as "proteogenomics". Such initial analysis enabled the identification of significant RNA-protein discordances, indicative of translational dysregulation. There is now a plethora of examples in both congenital and somatic ribosomopathies that support the differential translational output of specialized onco-ribosomes stemming from RP or ribosome biogenesis factor defects (reviewed in [32]). This provides an additional facet to the vast heterogeneity of cancer, but one that is beginning to be therapeutically exploited.

Over half of existing antibiotics bind and inhibit prokaryotic ribosomes. The selectivity of antibiotic binding is often provided by very subtle differences in ribosomal structure, and resistance to antibiotics is often enabled by changes as minor as a single chemical modification or the position of a single nucleotide in the ribosome [66,67]. Unique species-specific ribosomal features are being continuously discovered. For example, as noted above, the $80 \mathrm{~S}$ ribosome from the malarial P. falciparium harbors parasite-specific structural elements. These are currently being explored as targets for the rational design of small molecules to specifically inhibit the parasitic translational apparatus [68]. It should therefore be feasible to also develop small molecules that target RP-mutant cancer ribosomes, provided that these have distinguishing structural features. However, the exact composition of these specialized ribosomes has not been elucidated. In-depth structural studies by cryogenic electron microscopy or X-ray crystallography, combined with analysis of the protein composition, the rRNA modification status, and the spectrum of interacting proteins (ribo-interactome), would be required to characterize these specialized ribosomes in more detail. This might in turn encourage the development of "specialized" translation inhibitors. Indeed, new classes of translation inhibitors are being developed that selectively target translation of small subsets of mRNAs, with few off-target effects [69,70]. Illuminating the structure and function of oncogenic ribosomes, along with discovering their inhibitors, could enable a novel promising type of personalized therapy.

Such an approach might also find applications with regard to mitochondrial ribosomes, as a growing body of evidence suggests an important role for mitoribosomes in cancer progression. Cancer cells generally display higher rates of mitochondrial biogenesis [71] and their fitness is improved through a concerted increase in both cytosolic and mitochondrial translation [72]. Moreover, mitochondrial translation inhibition was proposed as an attractive therapeutic strategy for acute myeloid leukemia [71]. The clinical relevance of mitochondrial translation is further highlighted by the occurrence of mutations in mitochondrial RP genes, associated with mitochondrial dysfunction disorders (reviewed in [12]). For example, a recent case report highlights a common familial mitochondrial mutation that sensitizes the affected individuals to the ototoxicity of aminoglycoside antibiotics due to the mutation-induced structural changes in the mitoribosome [73]. While somatic mutations in mito-RP genes also regularly appear in cancer genomics datasets, their significance in cancer pathogenesis is not yet fully understood.

Finally, ribosome heterogeneity might play a causative role in another class of ribosome-mutant disorders: Ribosomopathies. These disorders stem from ribosome dysfunction and display a broad spectrum of phenotypic defects. However, most of these diseases also display similar hematopoietic deficiencies, such as bone marrow failure and anemia. This intriguing tissue specificity paradox begs the question of why mutations in the biochemical machine found in every single cell of the body, and with an essential role in every tissue, tend to have a more profound effect on hematopoietic cells. The notion that ribosomes can vary in composition between different tissues, as discussed above, may shed some light on this paradox. For example, a quarter of human ribosomal proteins exhibit tissue-specific expression, 
and primary hematopoietic cells display the most complex expression patterns [74]. Additionally, a recent study indicates that ribosomal proteins found mutated in ribosomopathies like Diamond Blackfan Anemia are substoichiometric and demarcate ribosomes with specialized functions [44]. This study demonstrated how haploinsufficiencies of specific ribosomal proteins particularly perturb the translation of specific mRNAs, which may disproportionately result in hematopoietic dysfunction. Moreover, while the precise roles of the recently discovered ufmylation, discussed above, remain to be determined, the available knockout mouse models for the enzymes of the ufmylation cascade show defects in erythrocyte differentiation and result in embryonic lethality [75]. This is highly similar to the defects arising from haploinsufficiency of some ribosomal proteins in several ribosomopathies. These initial studies suggest that the specialized composition of the translational machinery in hematopoietic tissues might make them more vulnerable to defects in ribosomal function and regulation.

\subsection{Designer Ribosomes}

Some of the first yeast molecular genetics studies involved screening for resistance to antibiotics. One of these, the peptidyltransferase inhibitor trichodermin, was used to clone the TCM1 gene [76]. Contemporaneously, a genetic screen for mutants unable to maintain the yeast killer virus identified a family of $M A K$ (MAintenance of Killer) genes, including $M A K 8$ [77]. A subsequent study demonstrated that both the TCM1 and MAK8 encoded ribosomal protein uL3 (RPL3) and that they both carried the W255C mutation [78], which was later shown to structurally alter the peptidyltransferase center, thus accounting for its ability to confer resistance to a broad range of peptidylteransferase inhibitors [79]. Importantly, this was the first demonstration that ribosomes could be manipulated to incorporate novel functions, i.e., antibiotic resistance. The list of human-made mutations in ribosomal proteins, in both bacteria and yeast, is long and growing [80]. rRNA is equally amenable to bioengineering approaches, including insertion of aptamers, which can be used to facilitate affinity-based applications [81]. More recently, both E. coli and S. cerevisiae ribosomes have been bioengineered to contain a single rRNA, greatly facilitating the creation of "designer" ribosomes [82,83]. Given the malleability of ribosomes and the expanding set of tools that can be used to create new variations, the theoretical possibilities are manifest. For example, ribosomes may be created to optimize synthesis of therapeutic proteins containing novel amino acids. They could be engineered to polymerize novel functionalized monomers or perhaps nanostrings having incredible strength or utility for their informational complexity. Indeed, it is not pure science fiction to contemplate creating ribosomes designed to function in microorganisms with a particular purpose, and we dare to speculate that such organisms may play roles in the terraforming of Mars, Europa, or Enceladus in the not-so-distant future.

\section{Final Remarks: Looking Backwards and Forwards}

The potential number of unique ribosomes is on the same order of magnitude as the number of stars in the visible universe [63], and like our universe, it is constantly expanding (Figure 2). Nevertheless, direct evidence for specialized ribosomes remains elusive, and failure to uncover such evidence is more prevalent than success [84]. Extraordinary claims require extraordinary evidence; thus, the criteria for establishing the existence of specialized ribosomes must be stringently defined. Proposals include the biochemical "one enzyme, one substrate" approach [63], as well as genetic methodologies, e.g., demonstrations of gain-of-function mutation and inducibility under specific physiological conditions [85]. However, it is now clear that ribosomal heterogeneity abounds. The remarkable durability of life in the face of at least five mass extinction events during the Earth's planetary history may be attributable to the remarkable degree of heterogeneity that can be tolerated by ribosomes. Given the challenges currently facing humankind, our future may, at least in part, depend on our ability to manipulate this central organelle. 


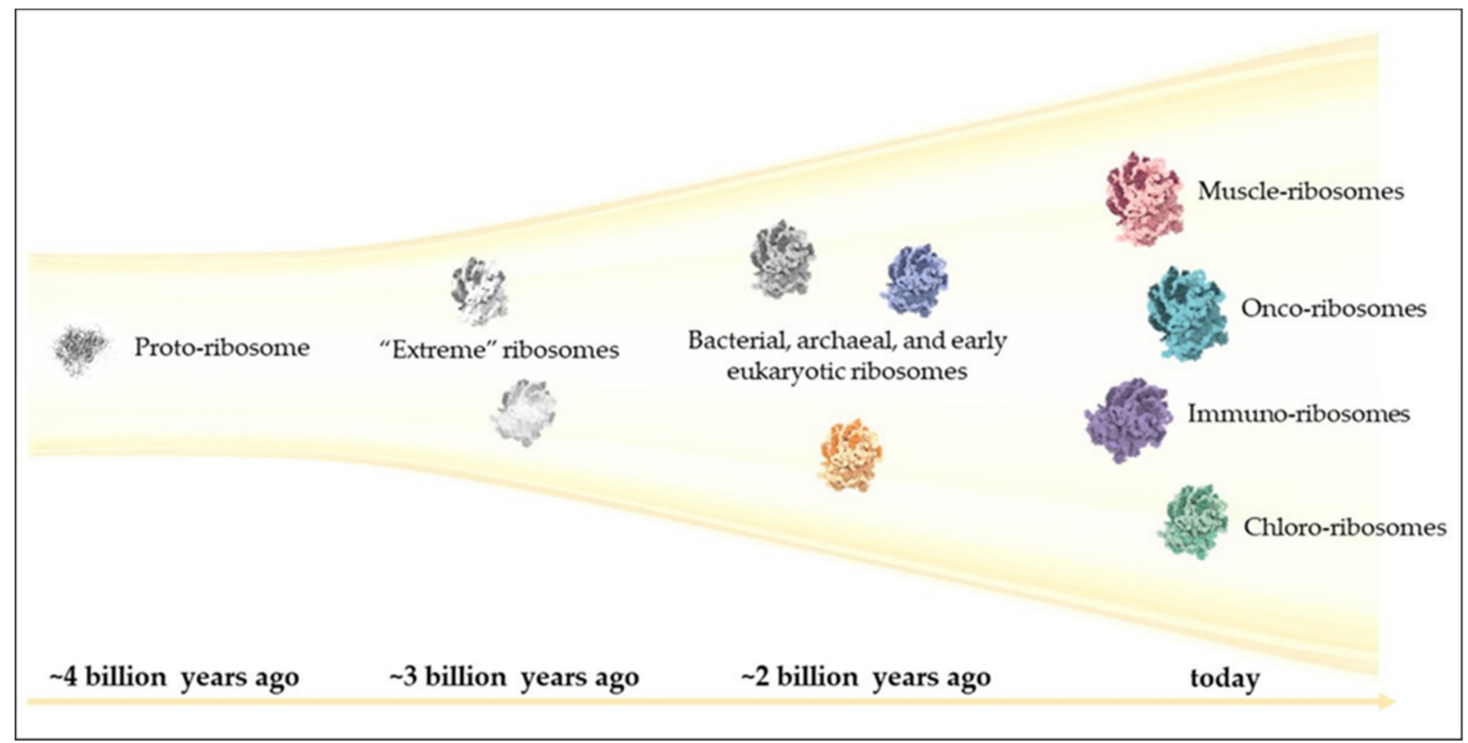

Figure 2. The expanding riboverse. The primordial ribosomal core, the proto-ribosome, is thought to have evolved approximately 4 billion years ago, marking the "Big Bang" of the riboverse. This ancient molecule continued to structurally and functionally evolve along with cellular evolution, diversifying and specializing to thrive in an increasing number of environments. Recent evidence suggests that in addition to inter-species specialization, ribosomal diversity also exists at the intra-organismal level.

Funding: This research was funded by a grant to JDD from the United States Department of Health and Human Services, National Institutes of Health, National Institute of General Medical Sciences, grant number R01 GM117177.

Acknowledgments: We would like to thank the members of the ribosome community for using this biomolecule to expand the boundaries of human knowledge. It is an honor to be associated with such a remarkable assembly of thoughtful, insightful, contentious and creative individuals. Sergey Sulima is currently employed by BioNTech $\mathrm{SE}$, which had no involvement in this work financially or otherwise.

Conflicts of Interest: The authors declare no conflict of interest.

\section{References}

1. Crick, F.H.C. Biochemical activities of nucleic acids. The present position of the coding problem. Brookhaven. Symp. Biol. 1959, 12, 35-39. [PubMed]

2. Mikkola, R.; Kurland, C.G. Is there a unique ribosome phenotype for naturally occurring Escherichia coli? Biochimie 1991, 73, 1061-1066. [CrossRef]

3. Wickner, R.B.; Leibowitz, M.J. Mak mutants of yeast: Mapping and characterization. J. Bacteriol. 1979, 140, 154-160. [PubMed]

4. Komili, S.; Farny, N.G.; Roth, F.P.; Silver, P.A. Functional specificity among ribosomal proteins regulates gene expression. Cell 2007, 131, 557-571. [CrossRef] [PubMed]

5. Bauer, J.W.; Brandl, C.; Haubenreisser, O.; Wimmer, B.; Weber, M.; Karl, T.; Klausegger, A.; Breitenbach, M.; Hintner, H.; von der Haar, T.; et al. Specialized yeast ribosomes: A customized tool for selective mRNA translation. PLoS ONE 2013, 8, e67609. [CrossRef]

6. Cheng, Z.; Mugler, C.F.; Keskin, A.; Hodapp, S.; Chan, L.Y.-L.; Weis, K.; Mertins, P.; Regev, A.; Jovanovic, M.; Brar, G.A. Small and Large Ribosomal Subunit Deficiencies Lead to Distinct Gene Expression Signatures that Reflect Cellular Growth Rate. Mol. Cell 2018. [CrossRef] [PubMed]

7. Genuth, N.R.; Barna, M. Heterogeneity and specialized functions of translation machinery: From genes to organisms. Nat. Rev. Genet. 2018, 19, 431-452. [CrossRef]

8. Genuth, N.R.; Barna, M. The Discovery of Ribosome Heterogeneity and Its Implications for Gene Regulation and Organismal Life. Mol. Cell 2018, 71, 364-374. [CrossRef] 
9. Xue, S.; Tian, S.; Fujii, K.; Kladwang, W.; Das, R.; Barna, M. RNA regulons in Hox 5'UTRs confer ribosome specificity to gene regulation and body plan formation. Nature 2015, 517, 33-38. [CrossRef] [PubMed]

10. Mageeney, C.M.; Ware, V.C. Specialized eRpL22 paralogue-specific ribosomes regulate specific mRNA translation in spermatogenesis in Drosophila melanogaster. Mol. Biol. Cell 2019, 30, 2240-2253. [CrossRef]

11. Mayor, M.; Queloz, D. A jupiter-mass companion to a solar-type star. Nature 1995, 378, 355-359. [CrossRef]

12. Greber, B.J.; Ban, N. Structure and Function of the Mitochondrial Ribosome. Annu. Rev. Biochem. 2016, 85, 103-132. [CrossRef]

13. Agrawal, R.K.; Sharma, M.R. Structural aspects of mitochondrial translational apparatus. Curr. Opin. Struct. Biol. 2012, 22, 797-803. [CrossRef] [PubMed]

14. Bieri, P.; Leibundgut, M.; Saurer, M.; Boehringer, D.; Ban, N. The complete structure of the chloroplast $70 S$ ribosome in complex with translation factor pY. EMBO J. 2017, 36, 475-486. [CrossRef] [PubMed]

15. Perez Boerema, A.; Aibara, S.; Paul, B.; Tobiasson, V.; Kimanius, D.; Forsberg, B.O.; Wallden, K.; Lindahl, E.; Amunts, A. Structure of the chloroplast ribosome with chl-RRF and hibernation-promoting factor. Nat. Plants 2018, 4, 212-217. [CrossRef] [PubMed]

16. Clemons, W.M., Jr.; May, J.L.; Wimberly, B.T.; McCutcheon, J.P.; Capel, M.S.; Ramakrishnan, V. Structure of a bacterial 30S ribosomal subunit at 5.5 A resolution. Nature 1999, 400, 833-840. [CrossRef] [PubMed]

17. Ban, N.; Nissen, P.; Hansen, J.; Capel, M.; Moore, P.B.; Steitz, T.A. Placement of protein and RNA structures into a 5 A-resolution map of the $50 \mathrm{~S}$ ribosomal subunit. Nature 1999, 400, 841-847. [CrossRef]

18. Cate, J.H.; Yusupov, M.M.; Yusupova, G.Z.; Earnest, T.N.; Noller, H.F. X-ray crystal structures of $70 S$ ribosome functional complexes. Science (80-.) 1999, 285, 2095-2104. [CrossRef] [PubMed]

19. Barandun, J.; Hunziker, M.; Vossbrinck, C.R.; Klinge, S. Evolutionary compaction and adaptation visualized by the structure of the dormant microsporidian ribosome. Nat. Microbiol. 2019, 1-7. [CrossRef] [PubMed]

20. Hashem, Y.; des Georges, A.; Fu, J.; Buss, S.N.; Jossinet, F.; Jobe, A.; Zhang, Q.; Liao, H.Y.; Grassucci, R.A.; Bajaj, C.; et al. High-resolution cryo-electron microscopy structure of the Trypanosoma brucei ribosome. Nature 2013, 494, 385-389. [CrossRef] [PubMed]

21. Waters, A.P.; Syin, C.; McCutchan, T.F. Developmental regulation of stage-specific ribosome populations in Plasmodium. Nature 1989, 342, 438-440. [CrossRef] [PubMed]

22. Parks, M.M.; Kurylo, C.M.; Batchelder, J.E.; Theresa Vincent, C.; Blanchard, S.C. Implications of sequence variation on the evolution of rRNA. Chromosom. Res. 2019, 27, 89-93. [CrossRef] [PubMed]

23. Gupta, V.; Warner, J.R. Ribosome-omics of the human ribosome. RNA 2014, 20, 1004-1013. [CrossRef] [PubMed]

24. Chaillou, T.; Zhang, X.; McCarthy, J.J. Expression of Muscle-Specific Ribosomal Protein L3-Like Impairs Myotube Growth. J. Cell. Physiol. 2016, 231, 1894-1902. [CrossRef] [PubMed]

25. Wen, Y.; Alimov, A.P.; McCarthy, J.J. Ribosome Biogenesis is Necessary for Skeletal Muscle Hypertrophy. Exerc. Sport Sci. Rev. 2016, 44, 110-115. [CrossRef]

26. Meskauskas, A.; Dinman, J.D. Ribosomal protein L3: Gatekeeper to the A-site. Mol.Cell 2007, 25, 877-888. [CrossRef] [PubMed]

27. Yewdell, J.W.; Antón, L.C.; Bennink, J.R. Defective ribosomal products (DRiPs): A major source of antigenic peptides for MHC class I molecules? J. Immunol. 1996, 157, 1823-1826.

28. Yewdell, J.W. Plumbing the sources of endogenous MHC class I peptide ligands. Curr. Opin. Immunol. 2007, 19, 79-86. [CrossRef]

29. Wei, J.; Yewdell, J.W. Immunoribosomes: Where's there's fire, there's fire. Mol. Immunol. 2018. [CrossRef]

30. Sulima, S.O.; Hofman, I.J.F.; De Keersmaecker, K.; Dinman, J.D. How ribosomes translate cancer. Cancer Discov. 2017, 7. [CrossRef]

31. Kampen, K.R.; Sulima, S.O.; Keersmaecker, K. De Rise of the specialized onco-ribosomes. Oncotarget 2018, 9, 35205-35206. [CrossRef] [PubMed]

32. Sulima, S.O.; Kampen, K.R.; De Keersmaecker, K. Cancer Biogenesis in Ribosomopathies. Cells $2019,8$. [CrossRef] [PubMed]

33. Girardi, T.; Vereecke, S.; Sulima, S.O.; Khan, Y.; Fancello, L.; Briggs, J.W.; Schwab, C.; De Beeck, J.O.; Verbeeck, J.; Royaert, J.; et al. The T-cell leukemia-associated ribosomal RPL10 R98S mutation enhances JAK-STAT signaling. Leukemia 2018, 32. [CrossRef] [PubMed] 
34. Kampen, K.R.; Sulima, S.O.; Verbelen, B.; Girardi, T.; Vereecke, S.; Rinaldi, G.; Verbeeck, J.; Op de Beeck, J.; Uyttebroeck, A.; Meijerink, J.P.P.; et al. The ribosomal RPL10 R98S mutation drives IRES-dependent BCL-2 translation in T-ALL. Leukemia 2019, 33, 319-332. [CrossRef] [PubMed]

35. Kampen, K.R.; Fancello, L.; Girardi, T.; Rinaldi, G.; Planque, M.; Sulima, S.O.; Loayza-Puch, F.; Verbelen, B.; Vereecke, S.; Verbeeck, J.; et al. Translatome analysis reveals altered serine and glycine metabolism in T-cell acute lymphoblastic leukemia cells. Nat. Commun. 2019, 10, 2542. [CrossRef] [PubMed]

36. Morgado-Palacin, L.; Varetti, G.; Llanos, S.; Gómez-López, G.; Martinez, D.; Serrano, M. Partial Loss of Rpl11 in Adult Mice Recapitulates Diamond-Blackfan Anemia and Promotes Lymphomagenesis. Cell Rep. 2015, 13, 712-722. [CrossRef] [PubMed]

37. Rao, S.; Lee, S.Y.; Gutierrez, A.; Perrigoue, J.; Thapa, R.J.; Tu, Z.; Jeffers, J.R.; Rhodes, M.; Anderson, S.; Oravecz, T.; et al. Inactivation of ribosomal protein L22 promotes transformation by induction of the stemness factor, Lin28B. Blood 2012, 120, 3764-3773. [CrossRef]

38. Ludwig, L.S.; Gazda, H.T.; Eng, J.C.; Eichhorn, S.W.; Thiru, P.; Ghazvinian, R.; George, T.I.; Gotlib, J.R.; Beggs, A.H.; Sieff, C.A.; et al. Altered translation of GATA1 in Diamond-Blackfan anemia. Nat. Med. 2014, 20, 748-753. [CrossRef]

39. Sulima, S.O.; Kampen, K.R.; Vereecke, S.; Pepe, D.; Fancello, L.; Verbeeck, J.; Dinman, J.D.; De Keersmaecker, K. Ribosomal Lesions Promote Oncogenic Mutagenesis. Cancer Res. 2019, 79, 320-327. [CrossRef]

40. Truitt, M.L.; Ruggero, D. New frontiers in translational control of the cancer genome. Nat. Rev. Cancer 2017, 17, 332. [CrossRef]

41. Kondrashov, N.; Pusic, A.; Stumpf, C.R.; Shimizu, K.; Hsieh, A.C.; Xue, S.; Ishijima, J.; Shiroishi, T.; Barna, M. Ribosome-mediated specificity in Hox mRNA translation and vertebrate tissue patterning. Cell 2011, 145, 383-397. [CrossRef] [PubMed]

42. Briggs, J.W.; Dinman, J.D. Subtractional Heterogeneity: A Crucial Step toward Defining Specialized Ribosomes. Mol. Cell 2017, 67, 3-4. [CrossRef] [PubMed]

43. Simsek, D.; Tiu, G.C.; Flynn, R.A.; Byeon, G.W.; Leppek, K.; Xu, A.F.; Chang, H.Y.; Barna, M. The mammalian ribo-interactome reveals ribosome functional diversity and heterogeneity. Cell 2017, 169, 1051-1065. [CrossRef] [PubMed]

44. Shi, Z.; Fujii, K.; Kovary, K.M.; Genuth, N.R.; Röst, H.L.; Teruel, M.N.; Barna, M. Heterogeneous ribosomes preferentially translate distinct subpools of mRNAs genome-wide. Mol. Cell 2017, 67, 71-83. [CrossRef] [PubMed]

45. Fujii, K.; Susanto, T.T.; Saurabh, S.; Barna, M. Decoding the Function of Expansion Segments in Ribosomes. Mol. Cell 2018, 72, 1013-1020.e6. [CrossRef]

46. Williamson, N.A.; Raliegh, J.; Morrice, N.A.; Wettenhall, R.E. Post-translational processing of rat ribosomal proteins. Ubiquitous methylation of Lys22 within the zinc-finger motif of RL40 (carboxy-terminal extension protein 52) and tissue-specific methylation of Lys4 in RL29. Eur.J.Biochem. 1997, 246, 786-793. [CrossRef] [PubMed]

47. Al-Hadid, Q.; Roy, K.; Chanfreau, G.; Clarke, S.G. Methylation of yeast ribosomal protein Rpl3 promotes translational elongation fidelity. RNA 2016, 22, 489-498. [CrossRef]

48. Arnold, R.J.; Saraswat, S.; Reilly, J.P. Analysis of Methylation, Acetylation, and Other Modifications in Bacterial Ribosomal Proteins; Humana: New York, NY, USA, 2019; pp. 293-307.

49. Little, R.H.; Grenga, L.; Saalbach, G.; Howat, A.M.; Pfeilmeier, S.; Trampari, E.; Malone, J.G. Adaptive Remodeling of the Bacterial Proteome by Specific Ribosomal Modification Regulates Pseudomonas Infection and Niche Colonisation. PLOS Genet. 2016, 12, e1005837. [CrossRef]

50. Małecki, J.; Dahl, H.-A.; Moen, A.; Davydova, E.; Falnes, P.Ø. The METTL20 Homologue from Agrobacterium tumefaciens Is a Dual Specificity Protein-lysine Methyltransferase That Targets Ribosomal Protein L7/L12 and the $\beta$ Subunit of Electron Transfer Flavoprotein (ETF $\beta$ ). J. Biol. Chem. 2016, 291, 9581-9595. [CrossRef]

51. Clarke, S.G. The ribosome: A hot spot for the identification of new types of protein methyltransferases. J. Biol. Chem. 2018, 293, 10438-10446. [CrossRef]

52. Hamidi, T.; Singh, A.K.; Veland, N.; Vemulapalli, V.; Chen, J.; Hardikar, S.; Bao, J.; Fry, C.J.; Yang, V.; Lee, K.A.; et al. Identification of Rpl29 as a major substrate of the lysine methyltransferase Set7/9. J. Biol. Chem. 2018, 293, 12770-12780. [CrossRef] [PubMed] 
53. El Motiam, A.; Vidal, S.; de la Cruz-Herrera, C.F.; Da Silva-Álvarez, S.; Baz-Martínez, M.; Seoane, R.; Vidal, A.; Rodríguez, M.S.; Xirodimas, D.P.; Carvalho, A.S.; et al. Interplay between SUMOylation and NEDDylation regulates RPL11 localization and function. FASEB J. 2019, 33, 643-651. [CrossRef] [PubMed]

54. Imami, K.; Milek, M.; Bogdanow, B.; Yasuda, T.; Kastelic, N.; Zauber, H.; Ishihama, Y.; Landthaler, M.; Selbach, M. Phosphorylation of the Ribosomal Protein RPL12/uL11 Affects Translation during Mitosis. Mol. Cell 2018, 72, 84-98.e9. [CrossRef] [PubMed]

55. Arif, A.; Jia, J.; Willard, B.; Li, X.; Fox, P.L. Multisite Phosphorylation of S6K1 Directs a Kinase Phospho-code that Determines Substrate Selection. Mol. Cell 2019, 73, 446-457.e6. [CrossRef] [PubMed]

56. Graifer, D.; Malygin, A.; Karpova, G. Hydroxylation of protein constituents of the human translation system: Structural aspects and functional assignments. Future Med. Chem. 2019, 11, 357-369. [CrossRef] [PubMed]

57. Sloan, K.E.; Warda, A.S.; Sharma, S.; Entian, K.-D.; Lafontaine, D.L.J.; Bohnsack, M.T. Tuning the ribosome: The influence of rRNA modification on eukaryotic ribosome biogenesis and function. RNA Biol. 2017, 14, 1138-1152. [CrossRef] [PubMed]

58. Monaco, P.; Marcel, V.; Diaz, J.-J.; Catez, F. 2'-O-Methylation of Ribosomal RNA: Towards an Epitranscriptomic Control of Translation? Biomolecules 2018, 8, 106. [CrossRef] [PubMed]

59. Krogh, N.; Jansson, M.D.; Häfner, S.J.; Tehler, D.; Birkedal, U.; Christensen-Dalsgaard, M.; Lund, A.H.; Nielsen, $\mathrm{H}$. Profiling of 2'-O -Me in human rRNA reveals a subset of fractionally modified positions and provides evidence for ribosome heterogeneity. Nucleic Acids Res. 2016, 44, 7884-7895. [CrossRef]

60. Tardu, M.; Jones, J.D.; Kennedy, R.T.; Lin, Q.; Koutmou, K.S. Identification and Quantification of Modified Nucleosides in Saccharomyces cerevisiae mRNAs. ACS Chem. Biol. 2019, 14, 1403-1409. [CrossRef]

61. Blattner, F.R.; Plunkett, G.; Bloch, C.A.; Perna, N.T.; Burland, V.; Riley, M.; Collado-Vides, J.; Glasner, J.D.; Rode, C.K.; Mayhew, G.F.; et al. The complete genome sequence of Escherichia coli K-12. Science 1997, 277, 1453-1462. [CrossRef]

62. Kurylo, C.M.; Parks, M.M.; Juette, M.F.; Zinshteyn, B.; Altman, R.B.; Thibado,J.K.; Vincent, C.T.; Blanchard, S.C. Endogenous rRNA Sequence Variation Can Regulate Stress Response Gene Expression and Phenotype. Cell Rep. 2018, 25, 236-248.e6. [CrossRef] [PubMed]

63. Dinman, J.D. Pathways to Specialized Ribosomes: The Brussels Lecture. J. Mol. Biol. 2016, 428, $2186-2194$. [CrossRef] [PubMed]

64. Parks, M.M.; Kurylo, C.M.; Dass, R.A.; Bojmar, L.; Lyden, D.; Vincent, C.T.; Blanchard, S.C. Variant ribosomal RNA alleles are conserved and exhibit tissue-specific expression. Sci. Adv. 2018, 4, eaao0665. [CrossRef] [PubMed]

65. Mertins, P.; Mani, D.R.; Ruggles, K.V.; Gillette, M.A.; Clauser, K.R.; Wang, P.; Wang, X.; Qiao, J.W.; Cao, S.; Petralia, F.; et al. Proteogenomics connects somatic mutations to signalling in breast cancer. Nature 2016, 534, 55-62. [CrossRef] [PubMed]

66. Lin, J.; Zhou, D.; Steitz, T.A.; Polikanov, Y.S.; Gagnon, M.G. Ribosome-Targeting Antibiotics: Modes of Action, Mechanisms of Resistance, and Implications for Drug Design. Annu. Rev. Biochem. 2018, 87, 451-478. [CrossRef] [PubMed]

67. Myasnikov, A.G.; Kundhavai Natchiar, S.; Nebout, M.; Hazemann, I.; Imbert, V.; Khatter, H.; Peyron, J.-F.; Klaholz, B.P. Structure-function insights reveal the human ribosome as a cancer target for antibiotics. Nat. Commun. 2016, 7, 12856. [CrossRef]

68. Wong, W.; Bai, X.; Brown, A.; Fernandez, I.S.; Hanssen, E.; Condron, M.; Tan, Y.H.; Baum, J.; Scheres, S.H. Cryo-EM structure of the Plasmodium falciparum $80 \mathrm{~S}$ ribosome bound to the anti-protozoan drug emetine. Elife 2014, 3. [CrossRef] [PubMed]

69. Lintner, N.G.; McClure, K.F.; Petersen, D.; Londregan, A.T.; Piotrowski, D.W.; Wei, L.; Xiao, J.; Bolt, M.; Loria, P.M.; Maguire, B.; et al. Selective stalling of human translation through small-molecule engagement of the ribosome nascent chain. PLOS Biol. 2017, 15, e2001882. [CrossRef]

70. Petersen, D.N.; Hawkins, J.; Ruangsiriluk, W.; Stevens, K.A.; Maguire, B.A.; O'Connell, T.N.; Rocke, B.N.; Boehm, M.; Ruggeri, R.B.; Rolph, T.; et al. A Small-Molecule Anti-secretagogue of PCSK9 Targets the 80S Ribosome to Inhibit PCSK9 Protein Translation. Cell Chem. Biol. 2016, 23, 1362-1371. [CrossRef]

71. Škrtić, M.; Sriskanthadevan, S.; Jhas, B.; Gebbia, M.; Wang, X.; Wang, Z.; Hurren, R.; Jitkova, Y.; Gronda, M.; Maclean, N.; et al. Inhibition of Mitochondrial Translation as a Therapeutic Strategy for Human Acute Myeloid Leukemia. Cancer Cell 2011, 20, 674-688. [CrossRef] 
72. Vendramin, R.; Verheyden, Y.; Ishikawa, H.; Goedert, L.; Nicolas, E.; Saraf, K.; Armaos, A.; Delli Ponti, R.; Izumikawa, K.; Mestdagh, P.; et al. SAMMSON fosters cancer cell fitness by concertedly enhancing mitochondrial and cytosolic translation. Nat. Struct. Mol. Biol. 2018, 25, 1035-1046. [CrossRef] [PubMed]

73. Ou, Y.-H.; Chen, A.W.-G.; Fan, J.-Y.; Cheng, W.-L.; Lin, T.-T.; Chen, M.-K.; Liu, C.-S. Aminoglycoside-associated nonsyndromic deafness and speech disorder in mitochondrial A1555G mutation in a family: A case report. Medicine (Baltimore) 2018, 97, e12878. [CrossRef] [PubMed]

74. Guimaraes, J.C.; Zavolan, M. Patterns of ribosomal protein expression specify normal and malignant human cells. Genome Biol. 2016, 17, 236. [CrossRef] [PubMed]

75. Tatsumi, K.; Yamamoto-Mukai, H.; Shimizu, R.; Waguri, S.; Sou, Y.-S.; Sakamoto, A.; Taya, C.; Shitara, H.; Hara, T.; Chung, C.H.; et al. The Ufm1-activating enzyme Uba5 is indispensable for erythroid differentiation in mice. Nat. Commun. 2011, 2, 181. [CrossRef] [PubMed]

76. Grant, P.G.; Schindler, D.; Davies, J.E. Mapping of trichodermin resistence in Saccharomyces cerevisiae: A genetic locus for a component of the 60 S ribosomal subunit. Genetics 1976, 83, 667-673. [PubMed]

77. Wickner, R.B.; Leibowitz, M.J. Chromosomal and non-chromosomal mutations affecting the "killer character" of Saccharomyces cerevisiae. Genetics 1974, 76, 423-432.

78. Wickner, R.B.; Porter-Ridley, S.; Fried, H.M.; Ball, S.G. Ribosomal protein L3 is involved in replication or maintenance of the killer double-stranded RNA genome of Saccharomyces cerevisiae. Proc. Natl. Acad. Sci. USA 1982, 79, 4706-4708. [CrossRef]

79. Jenner, L.; Melnikov, S.; de Loubresse, N.G.N.G.; Ben-Shem, A.; Iskakova, M.; Urzhumtsev, A.; Meskauskas, A.; Dinman, J.; Yusupova, G.; Yusupov, M. Crystal structure of the 80 S yeast ribosome. Curr. Opin. Struct. Biol. 2012, 22, 759-767. [CrossRef]

80. Dinman, J.D.; O'Connor, M. Mutants that affect recoding. In Recoding: Expansion of Decoding Rules Enriches Gene Expression; Atkins, J.F., Gesteland, R.F., Eds.; Nucelic Acids and Molecular Biology; Springer: New York, NY, USA; Dordrecht, The Nethterlands; Heidelberg, Germany; London, UK, 2010; ISBN 978-0-387-89381-5.

81. Golovina, A.Y.; Bogdanov, A.A.; Dontsova, O.A.; Sergiev, P. V Purification of 30 S ribosomal subunit by streptavidin affinity chromatography. Biochimie 2010, 92, 914-917. [CrossRef]

82. Orelle, C.; Carlson, E.D.; Szal, T.; Florin, T.; Jewett, M.C.; Mankin, A.S. Protein synthesis by ribosomes with tethered subunits. Nature 2015, 524, 119-124. [CrossRef]

83. Zhang, W.; Zhao, G.; Luo, Z.; Lin, Y.; Wang, L.; Guo, Y.; Wang, A.; Jiang, S.; Jiang, Q.; Gong, J.; et al. Engineering the ribosomal DNA in a megabase synthetic chromosome. Science 2017, 355, eaaf3981. [CrossRef] [PubMed]

84. Haag, E.S.; Dinman, J.D. Still Searching for Specialized Ribosomes. Dev. Cell 2019, 48, 744-746. [CrossRef] [PubMed]

85. Ferretti, M.B.; Karbstein, K. Does Functional Specialization of Ribosomes Really Exist? RNA 2019. rna.069823.118. [CrossRef] [PubMed]

(C) 2019 by the authors. Licensee MDPI, Basel, Switzerland. This article is an open access article distributed under the terms and conditions of the Creative Commons Attribution (CC BY) license (http://creativecommons.org/licenses/by/4.0/). 